\title{
Hematomas de erupção: relato de três casos clínicos em bebês
}

\author{
Eruption hematomas: report of 3 clinical cases in infants
}

\author{
Luiza Helena Silva de Almeida* \\ Marina Sousa Azevedo** \\ Fernanda Geraldo Pappen ${ }^{* * *}$ \\ Ana Regina Romano ${ }^{* * * *}$
}

\section{Resumo}

Introdução: Os cistos de erupção são considerados um tipo de cisto dentígero e podem ocorrer na dentição decídua. Essa patologia ocorre quando o dente apresenta dificuldade para vencer resistências e irromper na arcada dentária, permanecendo a face oclusal ou incisal de sua coroa recoberta por um capuz de mucosa gengival, favorecendo um processo inflamatório de natureza traumática. Objetivo: o objetivo deste artigo é apresentar três casos clínicos de hematomas de erupção associados aos dentes decíduos em bebês atendidos no projeto Atenção Odontológica Materno-Infantil da Faculdade de Odontologia da Universidade Federal de Pelotas, Rio Grande do Sul, Brasil, e a conduta adotada. Relato de casos: os casos apresentados são de uma menina de dez meses e de dois meninos, um com treze e outro de dezoito meses de idade, cujas mães relataram a presença de uma alteração de coloração azulada. Nos três casos foi realizada a drenagem do cisto devido ao relato de choro da criança desde o aprecimento do cisto, de alteração na cronologia de erupção e de dificuldade de alimentação da criança, respectivamente. Considerações finais: dessa forma, em caso de hematoma de erupção em bebês, cabe ao profissional orientar a família e, quando necessário, intervir, pois é um procedimento simples e resolutivo.

Palavras-chave: Lactante. Hematoma. Dente decíduo.

\section{Introdução}

Cistos odontogênicos são definidos como cistos que surgem a partir do epitélio odontogênico e ocorrem nas regiões entre dentes e ossos maxilares. A proliferação e/ou degeneração do epitélio leva ao desenvolvimento dessa condição ${ }^{1}$. A frequência de cistos odontogênicos em crianças é relativamente baixa $^{2}$. Um dos tipos mais comuns desses cistos são os cistos dentígeros, representando $24 \%$ de todas as lesões na população em geral ${ }^{3}$. Foi estimado que entre $4 \%$ a $9 \%$ dos cistos dentígeros ocorrem na primeira década de vida ${ }^{4,5}$.

A patogênese desse cisto é desconhecida, mas, aparentemente, ele se desenvolve pelo acúmulo de líquido entre o epitélio reduzido do orgão do esmalte e a coroa do dente. $\mathrm{O}$ cisto de erupção é análogo ao cisto dentígero no tecido mole. Desenvolve-se como resultado da separação do folículo dentário que envolve a coroa de um dente em erupção ${ }^{6}$, provocando um bloqueio da microinfiltração regional que ocorre pela mucosa gengival e o dente não irrompido ${ }^{7}$. Clinicamente, os cistos de erupção apresentam-se como uma tumefação mole que pode conter apenas líquido (aparência translúcida azulada) ou também pigmento hemoglobínico (aparência de hematoma). Assim, se houver um traumatismo na superfície dos cistos, levando à presença de sangue no interior da

\footnotetext{
Mestre em Odontopediatria, doutorando em Odontopediatria, Programa de Pós-Graduação em Odontologia, Universidade Federal Pelotas, Pelotas,-Rio Grande do Sul, Brasil.

Professora doutora em Odontopediatria, Departamento Social e Preventivo, Universidade Federal Pelotas, Pelotas, Rio Grande do Sul, Brasil.

* Professora doutora em Endodontia, Departamento Semiologia Clínica e Restauradora, Universidade Federal Pelotas, Pelotas, Rio Grande do Sul, Brasil.

**** Professora doutora em Odontopediatria, Departamento Social e Preventivo, Universidade Federal Pelotas, coordenadora do projeto Atenção Odontológica Materno-Infantil, Pelotas, Rio grande do Sul, Brasil.
} 
cavidade cística, eles apresentarão uma coloração purpúrea, sendo então chamados de hematomas de erupção ${ }^{7}$.

Essa patologia é mais comum na dentição permanente e em meninos ${ }^{8}$, sendo considerada rara em associação com dentes decíduos, com um acometimento de aproximadamente $0,7 \% \%^{5,9}$. Normalmente, na dentição decídua não há indicação de tratamento, apenas o acompanhamento, pois em geral a lesão rompe e o dente irrompe na cavidade bucal. Entretanto, em alguns casos, o quadro clínico pode apresentar-se doloroso e incômodo, necessitando de tratamento. Diante disso, o objetivo deste artigo é apresentar a conduta adotada em três casos clínicos de hematomas de erupção associados a dentes decíduos de pacientes atendidos no projeto de extensão Atenção Odontológica Materno-Infantil (AOMI), da Faculdade de Odontologia da Universidade Federal de Pelotas.

\section{Relato de casos}

Descrição do caso 1: a mãe de R.G.S., do sexo feminino, com dez meses de idade, procurou o Centro de Diagnóstico das Doenças da Boca (CDDB), da Faculdade de Odontologia da Universidade Federal Pelotas, relatando que há sete dias aparecera uma "bolinha" de coloração azulada na gengiva da sua filha. Após o exame clínico, verificou-se que a criança apresentava uma tumefação gengival mole de coloração azulada, depressível à palpação, na região de rebordo alveolar direito da maxila. Correspondendo à região do dente 52, medindo aproximadamente 1 centímetro. Após exame inicial da cavidade bucal, foi estabelecido o diagnóstico de cisto de erupção e a criança foi encaminhada para o projeto Aomi. Durante a anamnese, a mãe relatou que a criança estava "chorosa" desde o aparecimento do cisto. A partir da anamnese, com autorização para atendimento e realização do exame físico, em conjunto com a mãe, houve a decisão de realizar a intervenção.

Com o bebê em posição joelho a joelho, inicialmente foi realizada a anestesia tópica, o local foi seco com gaze e foi colocado gel de benzocaína a $20 \%$ (Benzotop $200 \mathrm{mg} / \mathrm{g}$ benzocaína. DFL, Indústrias e Comércios S.A., Rio de Janeiro, RJ, Brasil). O anestésico foi deixado sobre o cisto com auxílio de uma pinça clínica e gaze, por 2 minutos, conforme protocolo dos anestésicos, cuidando para colocar em pouca quantidade para não se dissolver em saliva, evitando escorrer para outros locais da cavidade bucal. Logo após, foi realizada uma perfuração com uma sonda exploradora (Figura 1a), com intuito de romper o tecido que cobria o cisto e drenar o conteúdo cístico (Figura 1b). A erupção do dente 52 ocorreu sem mais alterações.

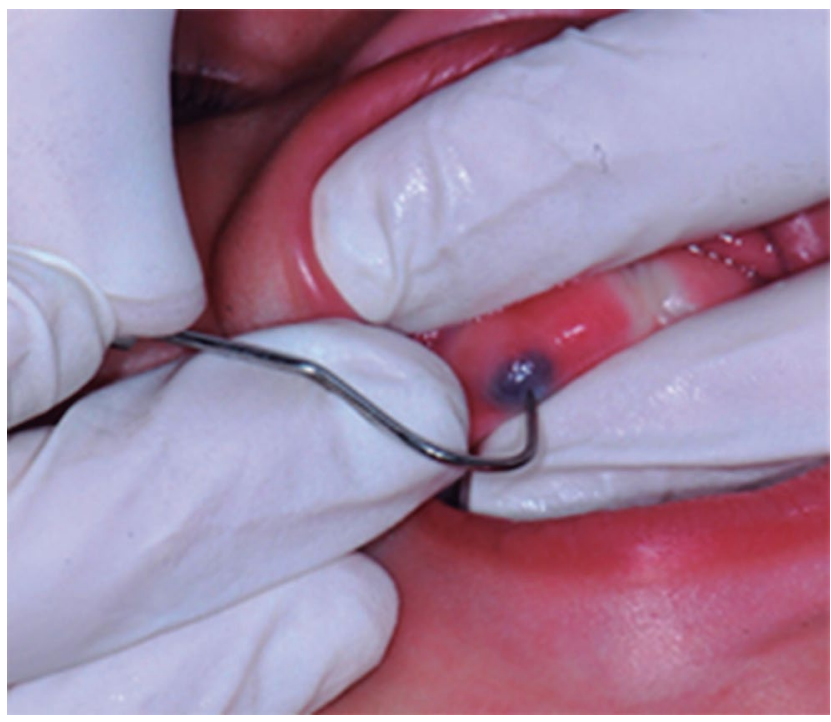

Figura 1a - Caso 1: hematomas de erupção do dente 52. Perfurando com sonda clínica o hematoma de erupção

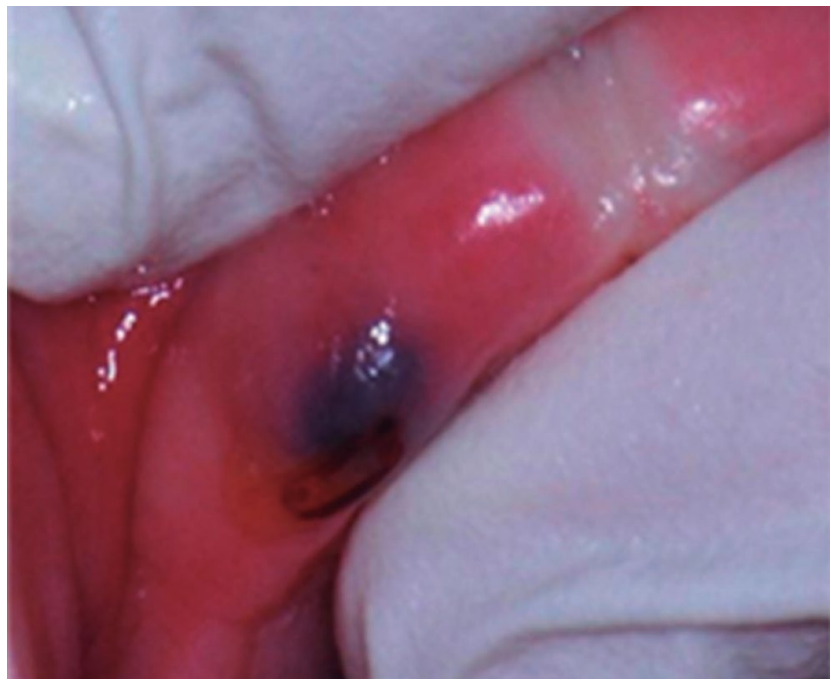

Figura 1b - Caso 1: hematomas de erupção do dente 52. Drenando o líquido cístico

Descrição do caso 2: a mãe de D.D.S, sexo masculino, com dezoito meses de idade, procurou atendimento do projeto AOMI, preocupada com a "lesão roxa na boca de seu filho". Após autorização escrita para o atendimento, foi conduzido o exame físico e observou-se uma tumefação gengival mole, depressível à palpação e de coloração azulada, em região de maxila esquerda, correspondente ao dente 64 , medindo aproximadamente 1,5 centímetros, conforme mostra a Figura 2a. Foi diagnosticado como hematoma de erupção de acordo com os sinais clínicos. A mãe relatou que a criança estava com dificuldade para se alimentar, então, optou-se pela drenagem na mesma sessão. O bebê foi colocado na posição joelho a joelho, e o tratamento realizado foi semelhante ao procedimento feito no caso 1: anestesia com anestésico tópico e perfuração no centro da lesão com uma sonda exploradora estéril (Figura 2b). Imediatamente após o procedimento, o conteúdo cístico foi drenado (Figura 2c). Esse pa- 
ciente apresentou mais quatro hematomas de erupção nos dentes segundos molares superiores e inferiores. Em dois deles foi realizada a intervenção e em menos de um mês eles estavam com a superfície oclusal livre. Nos dois outros casos a mãe aguardou, uma vez que ela estava esclarecida e o seu filho não sentiu incômodo, houve a erupção sem necessidade de intervenção.
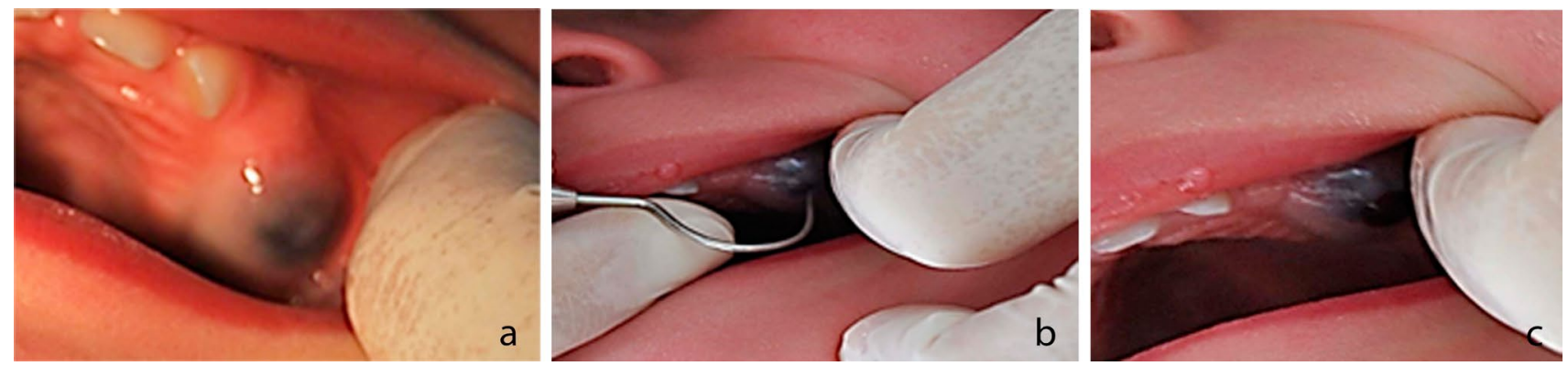

Figura 2 - Caso 2: hematomas de erupção do dente 64. a) aspecto clínico do hematoma; b) perfurando com sonda clínica; c) drenando o líquido cístico.

Descrição do caso 3: a mãe de A.B.C.S., do sexo masculino, com treze meses de idade, procurou o serviço de atendimento da AOMI com queixa de que "um dente não nasceu e que havia uma mancha azulada na gengiva de seu filho". De acordo com o relato da mãe, a menina estava chorosa e com dificuldade para se alimentar. Após o consentimento para o atendimento, o paciente foi conduzido para o exame físico, que confirmou a ausência do dente 61 e, no local, a presença de um hematoma de erupção com o tecido um pouco fibrosado e com alteração na sequência de erupção (Figura 3a). Foi planejada a realização de uma intervenção. Nesse caso, devido à maior resistência do tecido gengival, a opção foi, após a anestesia tópica, realizar anestesia local infiltrativa, usando $0,5 \mathrm{ml}$ de lidocaína a $2 \%$ com epinefrina 1: 100.000 (DFL, Indústrias e Comércios S.A., Rio de Janeiro, RJ, Brasil), e uma incisão com bisturi com lâmina 15 para drenagem (Figura 3b) para expor parte da coroa dentária (Figura 3c). Após a drenagem, o tecido foi apreendido com pinça reta e retirado com bisturi. $\mathrm{O}$ paciente ficou em acompanhamento e sem alterações até completar a dentição decídua.
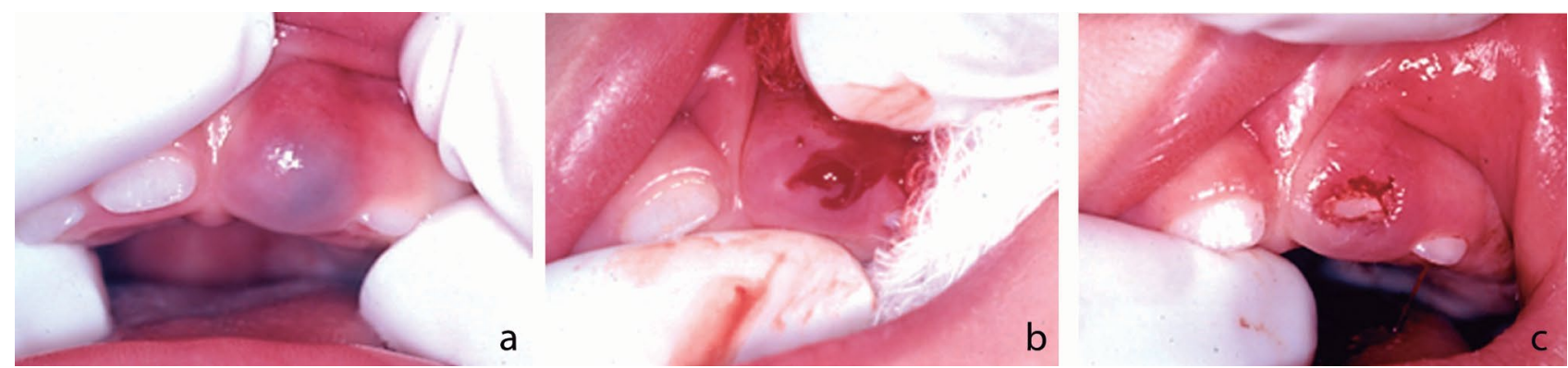

Figura 3 - Caso 3: hematomas de erupção do dente 61. a) aspecto clínico do hematoma; b) drenando o líquido cístico; c) aspecto clínico após exposição do dente

\section{Discussão}

As lesões císticas nos maxilares podem ser de origem odontogênica, não odontogênica, do desenvolvimento e inflamatória. Em crianças, $70 \%$ dos cistos tendem a ser de origem do desenvolvimento, enquanto $13,3 \%$ são de origem inflamatória ${ }^{10}$. Essa maior ocorrência de formação de cistos do desenvolvimento pode estar associada ao fato que, durante a infância, os ossos maxilofaciais, juntamente com as dentições decídua e permanente, estão em intenso e profundo desenvolvimento ${ }^{10,11}$.

O cisto de erupção está entre os cistos do desenvolvimento que podem ser observados na infância, sendo considerada uma variação distinta do cisto dentígero em tecido mole e definida como cisto do desenvolvimento do folículo dental ${ }^{12}$. Bodner ${ }^{10}$
(2002) avaliou 69 pacientes pediátricos com cistos, com idades entre um mês e dezesseisanos, e verificou a presença de cistos de erupção em $22 \%$ deles, sendo a idade média das crianças com esse diagnóstico de 4,7 anos.

A histogênese do cisto dentígero, incluindo o cisto de erupção, ainda é obscura e sua etiologia também não está definida, mas em dentes decíduos tem sido relacionada com um processo inflamatório ou traumático ${ }^{13-15}$.

Adewuimi et al. ${ }^{16}$ (2010) apresentaram o caso de um bebê com vinte meses de idade com escorbuto, decorrente da deficiência de vitamina $\mathrm{C}$, associado a isso lesões gengivais, dentre elas, o cisto de erupção. Eles afirmam que a irregularidade na dieta alimentar, com a deficiência de vitaminas, pode contribuir para a formação de tal patologia. Nos casos assistidos na Aomi, não foram investigados fatores 
nutricionais, mas as mães não relataram nenhuma alteração sistêmica relevante nesse sentido.

A ocorrência nos casos registrados neste estudo foi de 2:1 com relação ao sexo, dois meninos para uma menina, assim como a literatura aponta ${ }^{8}$.

A importância de relatar esses casos está na baixa prevalência dos cistos de erupção na dentição decídua. A maior ocorrência na dentição permanente pode ser justificada pelo fato de ser mais detectada, ou seja, a dentição decídua entra em erupção, geralmente, entre seis e 24 meses, uma época em que não se costuma levar a criança ao dentista ${ }^{17}$ e podem não ter o diagnóstico da presença do cisto, uma vez que a maior parte tem resolução espontânea e não apresenta sintomatologia. Conforme descrito por Bodner et al. ${ }^{8}$ (2004), estudando 24 casos de cistos de erupção, 8,3\% podem estar associados a dentes natais, $41,6 \%$ aos dentes decíduos, e $50 \%$ aos permanentes.

Considerando a localização, uma avaliação retrospectiva de 36 casos de cistos de erupção mostrou maior ocorrência na maxila em dentição permanente, e a maioria como um evento único entre cinco e nove anos de idade ${ }^{7}$. No entanto, também tem sido relatada com frequência a ocorrência nos primeiros molares permanentes inferiores ${ }^{18}$. Na dentição decídua, como é relatada maior ocorrência nos incisivos centrais decíduos ${ }^{19}$.

Os três casos descritos neste trabalho ocorreram na maxila, no incisivo lateral, no central e em dente posterior, ocorrendo três cistos em uma única criança, dois na mandíbula. A literatura mostra, mesmo que seja menos comum, que esses cistos podem ser bilaterais $^{19}$ e que podem ser verificados vários cistos de erupção em uma mesma criança ${ }^{20}$, como foi o caso 2.

O diagnóstico do cisto ou hematoma de erupção é essencialmente obtido pelo exame clínico, com a realização de uma anamnese cuidadosa e criteriosa, levando-se em consideração o tempo de aparecimento da lesão, relato ou não de desconforto. No exame físico, o aspecto clínico (coloração, tamanho, consistência) e localização são observados. Além disso, deve-se ter em mente a cronologia de erupção e a idade de erupção dos dentes decíduos, uma vez que os cistos de erupção ocorrem quando um dente está prestes a irromper. São lesões translúcidas, circunscritas, flutuantes, e com aumento de volume correspondendo ao local da erupção do dente. Quando a cavidade cística contém sangue, devido a trauma ou infecção, a coloração torna-se arroxeada ou azulada, por isso é denominada hematoma erupção, como nos casos relatados ${ }^{21}$. O diagnóstico diferencial é com hemangioma, cisto gengival do recém-nascido e granuloma piogênico ${ }^{22}$.

A conduta para esse tipo de lesão geralmente é a proservação do caso, porque frequentemente o cisto se rompe espontaneamente, permitindo a erupção do dente ${ }^{20}$. Porém, às vezes, a lesão pode trazer algum tipo de desconforto ao paciente, como coceira, dificuldade em se alimentar, irritação na re- gião, como ocorreu nos casos apresentados, fazendo com que fosse indicada uma pequena intervenção. A simples punção ou incisão foi o tratamento eletivo com intuito de drenar o fluido acumulado no cisto e aliviar os sintomas ${ }^{23}$.

O tratamento em bebês consiste em uma simples excisão com lâmina de bisturi ou perfuração com sonda pontiaguda do revestimento cístico, permitindo o alívio dos sintomas e erupção do dente. Nessa técnica, o indicado é a anestesia tópica, pois ela atinge aproximadamente $4 \mathrm{~mm}$ da mucosa e a perfuração da sonda não ultrapassa essa medida ${ }^{24,25}$. Também é importante salientar, com base nos protocolos de anestésicos, que o início da ação é rápido e se dá em aproximadamente 15 segundos quando aplicado sobre a mucosa bucal. A posologia indica o uso de aplicações de $0,5 \mathrm{~g}$ para que seja alcançado o efeito desejado até a dose máxima recomendada, de 2 g medida ${ }^{24,25}$.

Algumas vezes, quando além da sintomatologia do paciente, a presença de tecido fibroso e o estágio avançado de formação de raízes ${ }^{20}$ estão presentes, pode ser realizada a exposição de parte da coroa dentária, incisal em dentes anteriores ou oclusal dos posteriores, propiciando uma erupção mais rápida. $\mathrm{O}$ caso de A.B.C.S. teve essa indicação, sendo a intervenção um pouco mais invasiva, mas resolutiva.

Em casos em que ocorre a excisão cirúrgica do cisto, é possível conduzir o exame anatomopatológico, pois apresenta representatividade de tecido para a análise histológica com intuito de confirmação do diagnóstico ${ }^{20}$. O caso descrito por Kimura et al. ${ }^{20}$ (2014) mostrou que o cisto de erupção apresentou um epitélio estratificado paraceratinizado e uma cápsula cística composta por tecido conjuntivo frouxo e revestidas por um epitélio estratificado e o fluido cístico com exsudato, sangue e escassas células epiteliais.

\section{Considerações finais}

Assim, embora normalmente um cisto de erupção não requeira tratamento cirúrgico, pode ser necessário para ajudar a erupção dos dentes. A sintomatologia do paciente e o estágio de formação de raízes são fatores importantes para determinar a melhor abordagem, e cabe ao profissional, cirurgião-dentista que atende bebês, diagnosticar, orientar a família e, quando necessário, intervir de forma resolutiva.

\section{Abstract}

Eruption cysts are considered a type of dentigerous cyst and may occur in the deciduous dentition. This condition occurs when the eruptive force of the tooth is not enough to overcome the dental arch strength. Either the occlusal or the incisal face of the crown of the tooth remains covered by a hood of gingival mucosa, favoring 
an inflammatory process of traumatic nature. Objective: This paper aims to present three clinical cases of eruption hematomas associated with deciduous teeth, in infants treated at the project Maternal and Child Dental Care - School of Dentistry, Federal University of Pelotas, RS, Brazil; and to describe the conduct performed. Case reports: The cases presented are of a 10-month-old girl and two 13 and 18-month-old boys, whose mothers reported the presence of a bluish color change. In all three cases, the cysts were drained because of the mother's report of infant crying since the appearance of the cyst, changes in the chronology of eruption, and difficulties for feeding the child, respectively. Final considerations: Facing an eruption hematoma in infants, the professional should instruct the family and intervene whenever necessary, as it is a simple and resolute procedure.

Keywords: Infants. Hematoma. Deciduous tooth.

\section{Referências}

1. Neville BW, Damm DD, Allen A, Bouquout JE. Patologia Facial \& Maxilofacial. 2. ed. Rio de Janeiro: Guanabara; 2004. p. 569.

2. Manor E, Kachko L, Puterman MB, Szabo G, Bodner L. Cystic lesions of the jaws - a clinicopathological study of 322 cases and review of the literature. Int J Med Sci 2012; 9(1):20-6.

3. Kalaskar RR, Tiku A, Damle SG. Dentigerous cyst of anterior maxilla in a young child - A case report. J Indian Soc Pedod Prev Dent 2007; 25(4):187-90.

4. Freitas DQ, Tempest LM, Sicoli E, Lopes-Neto FC. Bilateral dentigerous cysts: review of the literature and report of an unusual case. Dentomaxillofac Radiol 2006; 35(6):464-8.

5. Shear M, Speight PM. Cysts of the oral and maxillofacial regions. 4. ed. Oxford: Blackwell Munksgaard; 2007.

6. Adelsperger J, Campbell JH, Coates DB, Summerlin DJ, Tomich CE. Early soft tissue pathosis associated with impacted third molars without pericoronal radiolucency. Oral Surg Med Oral Pathol Oral Radiol Endond 2000; 89(4):402-6.

7. Aguiló L, Cibrián R, Bagán JV, Gandía JL. Eruption cysts: retrospective clinical study of 36 cases. ASDC J Dent Child 1998; 65(2):102-6.

8. Bodner L, Goldstein J, Sarnat H. Eruption cysts: a clinical report of 24 new cases. J Clin Pediatr Dent 2004; 28(2):183-6.

9. Killy HC, Kay LW. An analysis of 471 benign cystic lesions of the jaws. Int Surg 1966; 46(6):540-8.

10. Bodner L. Cystic lesions of the jaws in children. Int J Pediat Otorhinolaryngol 2002; 62(1):25-9.

11. Lustmann J, Shear M. Radicular cysts arising from deciduous teeth. Int J Oral Surg 1985; 14(2):153-61.

12. Shafer WG, Hine MK, Levy BM. Patologia Bucal. 4. ed. Trad. Superv. Sylvio Bevilacqua. Rio de Janeiro: Interamaerica; 1985. p. 269-315.

13. Boyezuk MP, Berger JR. Identifying a deciduous dentigerous cyst. J Am Dent Assoc 1995; 126(5):643-6.

14. Kozelj V, Sotosek B. Inflammatory dentigerous cysts of children treated by tooth extraction and decompression - report of four cases. Br Dent J 1999; 187(11):587-90.

15. Naclério MG, Simões WA, Zindel Deboni MC, Chilvarquer I, Aparecida TA. Dentigerous cyst associated with an upper permanent central incisor: case report and literature review. J Clin Pediatr Dent 2002; 26(2):187-92.

16. Adewumi AO, Ashoor IF, Soares FM, Guelmann M, Novak DA. Eruption hematoma as a possible oral sign of infantile scurvy. Pediatr Dent 2010; 32(2):151-5.

17. Barros AJD, Bertoldi AD. Desigualdades na utilização e no acesso a serviços odontológicos: uma avaliação em nível nacional. Cien Saude Colet 2002; 7(4):709-17.

18. Anderson RA. Eruption cysts: A retrograde study. J Dent Child 1990; 57(2):124-7.

19. Seward MH. Eruption cyst an analysis of its clinical features. Oral Surg 1973; 31(1):31-55.

20. Kimura JS, Wanderley MT, Pinto-Junior DS, Zardetto CG. An Unusual Case of Four Simultaneous Eruption Cysts in an Infant. J Dent Child (chic) 2014; 81(1):38-41.

21. Dhawan GKK, Sanjay C, Shweta A. Eruption cysts: A series of two cases. Dent Res J 2012; 9(5):647-50.

22. Pinkham JR, Casamassimo PS, Tigue DJ, Fields HW, Nowak AJ. Pediatric dentistry: infancy through adolescence. 4. ed. St. Louis, Missouri: Sauders, An imprint of Elsevier; 2005.

23. Coser RM, Flório FM, Melo BP, Quaglio JM. Clinical Features of the eruption cyst. Rev Gaucha Odontol 2004; 52(3):180-3.

24. Friedman PM, Fogelman JP, Nouri K, Levine VJ, Ashinoff R. Comparative study of the efficacy of four topical anesthetics. Dermatol Surg 1999; 25(12):950-4.

25. Rosivack RG, Koenigsberg SR, Maxwell KC. An analysis of the effectiveness of two topical anesthetics. Anesth Prog 1990; 37(6):290-2.

Endereço para correspondência:

Marina Sousa Azevedo

Rua Gonçalves Chaves 457, $7^{\circ}$ andar, sala 704

96015-560 Pelotas, RS

Telefone: 32224305 ramal 127

E-mail: marinasazevedo@hotmail.com

Recebido: 09-10/14. Aceito: 09/06/15 